\title{
Enhancement of Solubility and Improvement of Dissolution Rate of Atorvastatin Calcium Prepared as Nanosuspension Ahmed H. Ali", ${ }^{*}$ and Shaimaa N. Abd-Alhammid"
}

"Department of Pharmaceutics, College of Pharmacy, University of Baghdad, Baghdad, Iraq

Abstract

Atorvastatin calcium has a problem of very slightly aqueous solubility $(0.1-1 \mathrm{mg} / \mathrm{ml})$. Nanosuspension technique applied to improve atorvastatin calcium dissolution profile. The aim of this study is to formulate atorvastatin calcium as a nanosuspension to enhance its dissolution.

Thirty one formula were prepared to evaluate the effect of ; polymer type, polymer: drug ratio, speed of homogenization, temperature of preparation and inclusion of co-stabilizer in addition to the primary one; using solvent-anti-solvent precipitation method under high power of ultra-sonication. In this study, five types of stabilizers (TPGS, PVP K30, HPMC E5, HPMC E15, and Tween80) were used in three different concentrations 1:1, 1:0.75 and 1:0.5 for preparing of formulations. At the same time, Tween80 and sodium lauryl sulphate had been added as a co-stabilizer in selected formulations.

Atorvastatin calcium nanosuspension was evaluated for particle size, poly dispersity index (PDI), zeta potential, crystal form and surface morphology. Finally, the results of particle size analysis revealed reduced nanoparticulate size to $81 \mathrm{~nm}$ for optimized formula F18 ( containing drug : polymer : co-sabilizer ratio 1:1:0.5 ) with the enhancement of in-vitro dissolution profile up to $90 \%$ compared to $44 \%$ percentage cumulative release for the reference atorvastatin calcium powder in phosphate buffer $\mathrm{pH} 6.8$ media.

Furthermore, saturation solubility of freeze dried Nanosuspension showed 3.3, 3.8, and 3.7 folds increments in distilled water, $0.1 \mathrm{~N} \mathrm{HCl}$ and phosphate buffer $\mathrm{pH} 6.8$, respectively.

The freeze dried powder was formulated as hard gelatin capsules and evaluated according to the USP specifications of the drug content and disintegration time.

As a conclusion; formulation of poorly water soluble atorvastatin calcium as nanosuspension significantly improved the dissolution rate of the drug and enhanced its solubility.

Key words: Atorvastatin calcium, Nanosuspension, In-vitro dissolution and saturation solubility.

$$
\begin{aligned}
& \text { تحسين الأوباتية وتحسين معدل انحلال اتورفاستاتين كالسيوم بصيغة جزيئات تعليق نانوي }
\end{aligned}
$$

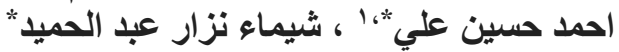

$$
\begin{aligned}
& \text { * فرع الصيدلانيات ، كلية الصيدلة ،جامعة بغداد ، بغداد ، العراق . }
\end{aligned}
$$

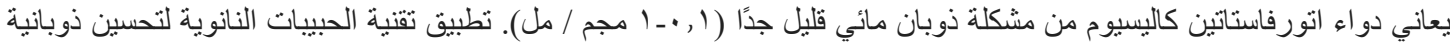

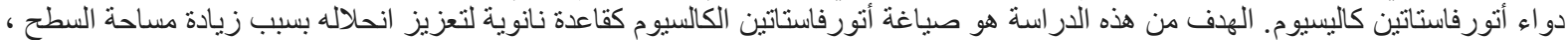
وفقًا لمعادلة نويز وينتي.

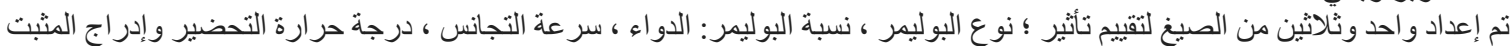

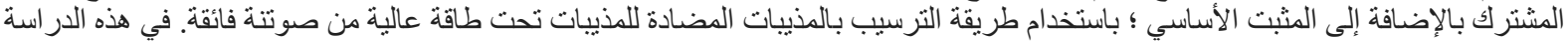

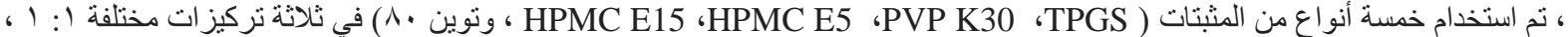

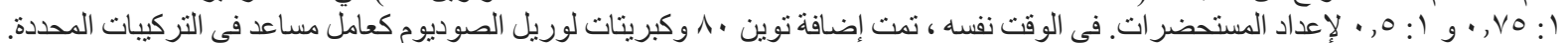

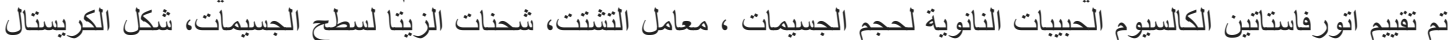

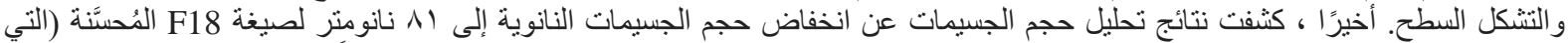

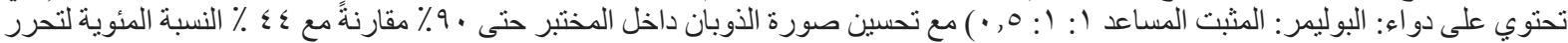

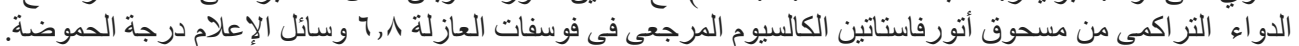

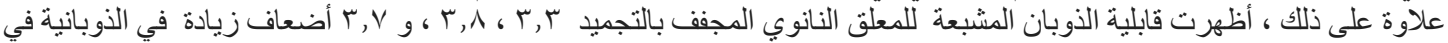

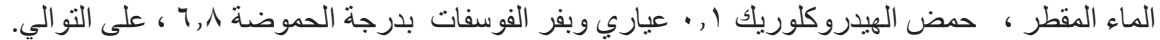
وقد تم صياغة كبسولات الجيلاتين الصلب من المسحوق النانوي المجف بالتجميد وتقييمها وفقا لمو اصفات USP من محتوى الدواء ووقت التفكك. وبذلك يمكن الاستتناج ان صياغة أتورفاستاتين الكالسيوم القليل الذوبان جدا في الماء بصيغة معلق نانوي ادت الى تحسن كبير في حل

الكلمات المفتاحية: اتورفاستاتين كاليسيوم ، معلق نانوي ، معدل التحلل المختبري والأوباتية المشبعة.

${ }^{1}$ Corresponding author: E-mail: ahali858@yahoo.com

Received: $15 / 12 / 2018$

Accepted: 9 /4 /2019

Iraqi Journal of Pharmaceutical Sciences 


\section{Introduction}

Formulating poorly water soluble drugs to obtain a suitable bioavailability has become a serious defy in scientific, industrial, and medical issue. Limitedness of particle size reduction with conventional approaches made researchers to look for new technologies for size reduction.

Nanotechnology innovation made this possible; a technique included nanosuspension, nanoemulsion, and several other nominated particulates on nano size range (below 1 micron particle diameter). Nanosizing is the modern approach for enhancing dissolution of poorly water soluble drug substances. Reducing particle size significance is increasing surface area of contact between solid particulate and dissolving medium ${ }^{(1)}$. Inclusion of stabilizers in nanosuspension formulation are of critical significance. An essential role of stabilizers is to compensate the additional non-bound energy of newly revealed surfaces. Rigorously wetting drug particulates, hindering Ostwald ripening and agglomeration of nano suspension particulates are the most important advantages of adding pharmaceutical stabilizers ${ }^{(2)}$.

The widely used techniques of stabilization are steric and/or electrostatic stabilization, both ionic surfactants and charged polymers act as electrostatic stabilizers and non-ionic surfactants act as steric stabilizers ${ }^{(3)}$

The specific characteristic of Vitamin E TPGS as solubilizer and stabilizer made to the selection of this surfactant for the nano formulation approach. Most widely applied pharmaceutical excipients as polymeric stabilizers are polymeric semisynthetic polysaccharide based non-ionic stabilizer like HPMC E5 and HPMC E15, the synthetic linear polymers polyvinyl pyrrolidone (PVP K30), Non-ionic surfactant stabilizers, such as polysorbate (Tween80) and VitaminE-TPGS (TPGS), which is non-ionic surfactant water soluble derivative of Vitamin $\mathrm{E}$. While for electrostatic stabilizers anionic surfactant like sodium lauryl sulphate (SLS) used in this study ${ }^{(4)}$.

Two types of stabilizers could be used for best stability of nano suspension, polymeric and surfactant type stabilizers.

The surface energy in drug-polymer binding is unclear and not specifically determined for polymeric semisynthetic polysaccharide based nonionogenic stabilizer (HPMC stabilizers). While it is of greater importance in PVP based synthetic linear polymers ${ }^{(5)}$. Stabilizers applied to the formulation of nanocrystal should adsorb to the nanocrystal surface of drug particulate and results in steric stabilization ${ }^{(6)}$.

Maintenance of stability of nanocrystalline structure is of great significance results from polymer steric stabilization. Successful stabilization requires tight and fastened adsorption and prolonged desorption with steric repulsion ${ }^{(7)}$. Zeta potential is a critical evaluation element broadly approached to forecast nanosuspension stability. The predicted stability increased as the ZP increased ( values greater than $+25 \mathrm{mV}$ or less than $-25 \mathrm{mV}$ typically have high degrees of stability) ${ }^{(8)}$.

Lyophilization, broadly applied in drying process of pharmaceutical industry for increasing stability ${ }^{(9-10)}$.

Atorvastatin is HMG CoA reductase (HMGR) inhibitor the rate-controlling stage in intracellular cholesterol synthesis, chemical structure is in figure $1^{(11)}$.

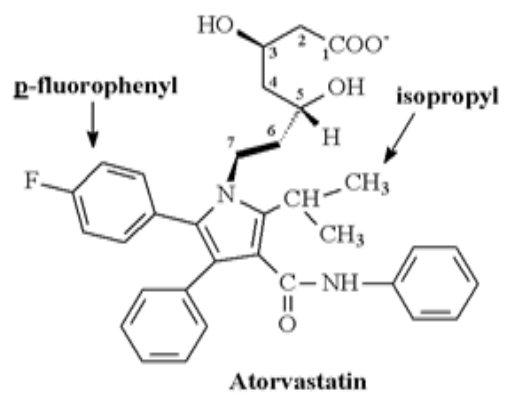

Figure 1. Chemical structure of atorvastatin calcium $^{(11)}$.

The aim of this study was to formulate atorvastatin calcium nanosuspension by the use of solventanisolvent technique under high power sonicator. An attempt to enhance atorvastatin solubility and improve dissolution rate.

\section{Materials and Method Materials}

Atorvastatin calcium was obtained as a gift from Pioneer pharmaceutical company /Iraq. Polyvinyl pyrolidone (PVP K30), vitamin Etocopherol TPGS, Hydroxypropyl methyl cellulose E5 and E 15, PVP, Sodium lauryl sulphate were purchased from PubChem. Company, China. Methanol laboratory grade and all other solvents obtained from college of pharmacy/university of Baghdad. Di-sodium hydrogen phosphate, Potassium dihydrogen phosphate.

\section{Method \\ Preparation of atorvastatin calcium nanosuspension by liquid solvent-antisolvent addition}

Atorvastatin calcium nanosuspension was prepared by liquid solvent- anti solvent precipitation under Ultra-sonication technique, in this method, $60 \mathrm{mg}$ of Atorvastatin calcium was dissolved in $3 \mathrm{ml}$ of organic solvent (methanol) to prepare organic phase ${ }^{(12)}$. On the other hand, aqueous phase prepared by dissolving specific weight of different types of stabilizer ( PVP, TPGS , Tween80, HPMC E5 and HPMC E15 ) and co-stabilizers ( SLS and Tween 80 ) in $25 \mathrm{ml}$ distilled water, different concentrations prepared of each polymer as mentioned in table 1 . Then the organic phase on steady rate ( 20 drops / minute) added to aqueous 
solution, with the shearing effect of homogenizer (differing speeds used 1500, and 3000).Preparations after homogenization stage, subjected to probe sonication for 20 minutes, with pulse period of $5 \mathrm{sec}$. off and $10 \mathrm{sec}$. on; $80 \%$ sonication power applied ${ }^{(13}$, 14). According to the study, nanosuspension were prepared as demonstrated in table 1 .

Table 1. Nanosuspension formulations prepared by solvent-antisolvent precipitation under sonication

\begin{tabular}{|c|c|c|c|c|c|c|c|c|}
\hline $\begin{array}{l}\text { Formula } \\
\text { no. }\end{array}$ & Stabilizer & $\begin{array}{l}\text { Drug : } \\
\text { Stabilizer } \\
\text { ratio }\end{array}$ & $\begin{array}{l}\text { Stirring } \\
\text { speed }\end{array}$ & $\begin{array}{c}\text { Co- } \\
\text { Stabilizer }\end{array}$ & $\begin{array}{c}\text { Drug : } \\
\text { CO- } \\
\text { Stabilizer } \\
\text { ratio }\end{array}$ & Temp. & $\begin{array}{l}\text { Particle size } \\
\text { nm }\end{array}$ & PDI \\
\hline F1 & HPMC E5 & $1: 1$ & 1500 & - & 0 & $25^{\circ} \mathrm{C}$ & 930 & 0.375 \\
\hline F2 & HPMC E5 & $1: 0.75$ & 1500 & - & 0 & $25^{\circ} \mathrm{C}$ & 1364 & 0.391 \\
\hline F3 & HPMC E5 & $1: 0.5$ & 1500 & - & 0 & $25^{\circ} \mathrm{C}$ & 1909 & 0.339 \\
\hline F4 & HPMC E15 & $1: 1$ & 1500 & - & 0 & $25^{\circ} \mathrm{C}$ & 3885 & 0.428 \\
\hline F5 & HPMC E15 & $1: 0.75$ & 1500 & - & 0 & $25^{\circ} \mathrm{C}$ & 4430 & 0.448 \\
\hline F6 & HPMCE15 & $1: 0.5$ & 1500 & - & 0 & $25^{\circ} \mathrm{C}$ & 6349 & 0.462 \\
\hline F7 & PVP-K30 & $1: 1$ & 1500 & - & 0 & $25^{\circ} \mathrm{C}$ & 100 & 0.058 \\
\hline F8 & PVP-K30 & $1: 0.75$ & 1500 & - & 0 & $25^{\circ} \mathrm{C}$ & 632 & 0.191 \\
\hline F9 & PVP-K30 & $1: 0.5$ & 1500 & - & 0 & $25^{\circ} \mathrm{C}$ & 771 & 0.354 \\
\hline F10 & Tween80 & $1: 1$ & 1500 & - & 0 & $25^{\circ} \mathrm{C}$ & 493 & 0.015 \\
\hline F11 & Tween80 & $1: 0.75$ & 1500 & - & 0 & $25^{\circ} \mathrm{C}$ & 551 & 0.189 \\
\hline F12 & Tween80 & $1: 0.5$ & 1500 & - & 0 & $25^{\circ} \mathrm{C}$ & 1932 & 0.550 \\
\hline F13 & TPGS & $1: 1$ & 1500 & - & 0 & $25^{\circ} \mathrm{C}$ & 835 & 0.316 \\
\hline F14 & TPGS & $1: 0.75$ & 1500 & - & 0 & $25^{\circ} \mathrm{C}$ & 1845 & 0.216 \\
\hline F15 & TPGS & $1: 0.5$ & 1500 & - & 0 & $25^{\circ} \mathrm{C}$ & 3551 & 0.348 \\
\hline F16 & HPMC E5 & $1: 1$ & 1500 & Tween80 & $1: 0.5$ & $25{ }^{\circ} \mathrm{C}$ & 685 & 0.015 \\
\hline F17 & PVP-K30 & $1: 1$ & 1500 & Tween80 & $1: 0.5$ & $25^{\circ} \mathrm{C}$ & 246 & 0.139 \\
\hline F18 & TPGS & $1: 1$ & 1500 & Tween80 & $1: 0.5$ & $25^{\circ} \mathrm{C}$ & 81 & 0.115 \\
\hline F19 & HPMC E5 & $1: 1$ & 1500 & SLS & $1: 0.5$ & $25^{\circ} \mathrm{C}$ & 166 & 0.005 \\
\hline F20 & PVP-K30 & $1: 1$ & 1500 & SLS & $1: 0.5$ & $25^{\circ} \mathrm{C}$ & 147 & 0.147 \\
\hline F21 & TPGS & $1: 1$ & 1500 & SLS & $1: 0.5$ & $25^{\circ} \mathrm{C}$ & 101 & 0.151 \\
\hline F22 & HPMC E5 & $1: 1$ & 3000 & - & 0 & $25^{\circ} \mathrm{C}$ & 366 & 0.005 \\
\hline F23 & HPMC E15 & $1: 1$ & 3000 & - & 0 & $25^{\circ} \mathrm{C}$ & 3375 & 0.167 \\
\hline F24 & PVP-K30 & $1: 1$ & 3000 & - & 0 & $25{ }^{\circ} \mathrm{C}$ & 119 & 0.005 \\
\hline F25 & Tween80 & $1: 1$ & 3000 & - & 0 & $25^{\circ} \mathrm{C}$ & 404 & 0.201 \\
\hline F26 & TPGS & $1: 1$ & 3000 & - & 0 & $25^{\circ} \mathrm{C}$ & 670 & 0.005 \\
\hline F27 & HPMC E5 & $1: 1$ & 1500 & - & 0 & $10^{\circ} \mathrm{C}$ & Not nano & - \\
\hline F28 & HPMC E15 & $1: 1$ & 1500 & - & 0 & $10^{\circ} \mathrm{C}$ & Not nano & - \\
\hline F29 & PVP-K30 & $1: 1$ & 1500 & - & 0 & $10^{\circ} \mathrm{C}$ & 93 & 0.047 \\
\hline F30 & Tween80 & $1: 1$ & 1500 & - & 0 & $10^{\circ} \mathrm{C}$ & 92 & 0.039 \\
\hline F31 & TPGS & $1: 1$ & 1500 & - & 0 & $10{ }^{\circ} \mathrm{C}$ & 77 & 0.137 \\
\hline
\end{tabular}




\section{Saturation solubility determination}

Determination of saturation solubility of atorvastatin calcium is approached by the addition of excess amount of pure powder drug to $10 \mathrm{ml}$ of each media and the tubes maintained in an incubator shaker at $25^{\circ} \mathrm{C}$ for $48 \mathrm{hr}$. The dissolved drug quantitatively determined by centrifugation of each sample at $4000 \mathrm{rpm}$ for $20 \mathrm{~min}$ and the supernatant filtered through 0.22 micrometer syringe filter and diluted with respective media. The diluted samples, along with an appropriate standard curve, were analyzed by UV spectrophotometer at $\lambda \max$ to determine the dissolved quantity of atorvastatin calcium ${ }^{(15)}$.

Measurement of particle size and poly dispersity index

Using Nano Brookhaven particle size analyzer, average particle size and poly dispersity index were measured ${ }^{(16)}$. Influence of types of stabilizers used, according to table 1, to prepare atorvastatin nanosuspension, formulas numbered F1, F4, F7, F10 and F13 were prepared to explore the different results with each polymer type. All polymers used in preparing atorvastatin calcium nanosuspension used in three concentrations to explore the impact of stabilizer concentration on prepared nanosuspension. Formulas F2, F3, F5, F6, $\mathrm{F} 8, \mathrm{~F} 9, \mathrm{~F} 11, \mathrm{~F} 12, \mathrm{~F} 14$ and F15 formulated to evaluate the effect of type of polymer on particle size and PDI of obtained nanosuspension.

Incorporation of secondary stabilizer (SLS or Tween80) on the nanosuspension of atorvastatin calcium was considered one of the most important formulation factors. Formulations F16, F17, F18, F19, F20 and F21 demonstrated the influence of this impact. Both steric-steric and steric-electrostatic mechanisms investigated at this stage of the study. Influence of stirring speed evaluated at two different speeds (3000 and $1500 \mathrm{rpm}$ ) on homogenizer. Formulae F22, F23, F24, F25 and F26) were tested for study the influence of homogenization speed on nanosuspension formulation speeds. The influence of temperature on the size reduction of nanosuspension particles were evaluated in this study. Therefore, formulas F27, F28, F29, F30 and F31 were prepared at $10^{\circ} \mathrm{C}$ to demonstrate the impact of preparation condition at low temperature.

\section{Zeta potential evaluation of nanosuspension}

Zeta-potential evaluated by the use of zetasizer (Zetasizer Nano ZS, Malvern instrument, Worcestershire, UK) ${ }^{(17)}$. The characteristics of surface charge were studied to assess the stability of the prepared nanosuspension. Minimum limit needed for electrostatic stabilization of nanosuspension is $\pm 30 \mathrm{mv}$, and for steric stabilization of $\pm 20 \mathrm{mv}(1)$. Table 2 zeta potential values for ten formulations ${ }^{(17)}$.

Table 2. Zeta potential values for ten formulations of prepared total 31 formulae.

\begin{tabular}{|c|c|c|c|c|c|c|c|c||}
\hline $\begin{array}{c}\text { Formula } \\
\text { no. }\end{array}$ & Stabilizer used & Co-Stabilizer & $\begin{array}{c}\text { Mechanism of } \\
\text { stabilization }\end{array}$ & $\begin{array}{c}\text { Speed of } \\
\text { stirring }\end{array}$ & Temp. & $\begin{array}{c}\text { Particle } \\
\text { size }\end{array}$ & PDI & $\begin{array}{c}\text { Zeta } \\
\text { potential }\end{array}$ \\
\hline F17 & PVP K30 & Tween80 & Steric-Steric & $1500 \mathrm{rpm}$ & $25^{\circ} \mathrm{C}$ & $246 \mathrm{~nm}$ & 0.139 & -28.52 \\
\hline F18 & TPGS & Tween80 & Steric-Steric & $1500 \mathrm{rpm}$ & $25^{\circ} \mathrm{C}$ & $81 \mathrm{~nm}$ & 0.115 & -26.11 \\
\hline F20 & PVP K30 & SLS & Steric-Electrostatic & $1500 \mathrm{rpm}$ & $25^{\circ} \mathrm{C}$ & $147 \mathrm{~nm}$ & 0.147 & -34.42 \\
\hline F21 & TPGS & SLS & Steric-Electrostatic & $1500 \mathrm{rpm}$ & $25^{\circ} \mathrm{C}$ & $101 \mathrm{~nm}$ & 0.151 & -34.95 \\
\hline F24 & PVP K30 & - & Steric stabilization & $3000 \mathrm{rpm}$ & $25^{\circ} \mathrm{C}$ & $119 \mathrm{~nm}$ & 0.005 & -30.7 \\
\hline F25 & Tween80 & - & Steric stabilization & $3000 \mathrm{rpm}$ & $25^{\circ} \mathrm{C}$ & $404 \mathrm{~nm}$ & 0.201 & -24.10 \\
\hline F26 & TPGS & - & Steric stabilization & $3000 \mathrm{rpm}$ & $25^{\circ} \mathrm{C}$ & $670 \mathrm{~nm}$ & 0.005 & -22.67 \\
\hline F29 & PVP K30 & - & - & $1500 \mathrm{rpm}$ & $10^{\circ} \mathrm{C}$ & $93 \mathrm{~nm}$ & 0.47 & -32.21 \\
\hline F30 & Tween80 & - & Steric stabilization & $1500 \mathrm{rpm}$ & $10^{\circ} \mathrm{C}$ & $92 \mathrm{~nm}$ & 0.039 & -28.11 \\
\hline F31 & TPGS & - & Steric stabilization & $1500 \mathrm{rpm}$ & $10^{\circ} \mathrm{C}$ & $77 \mathrm{~nm}$ & 0.137 & -33.64 \\
\hline
\end{tabular}

\section{In-vitro dissolution profile of nanosuspension}

Volume of nanosuspension equivalent to $20 \mathrm{mg}$ atorvastatin calcium was taken into dialysis membrane (Mw cutoff 12,000-14,000 Hi-media), and fixed to paddle of USP dissolution apparatusType II applying rotation speed of $75 \mathrm{rpm}$. Then $0.1 \mathrm{~N} \mathrm{HCl}$ and phosphate buffer $\mathrm{pH} 6.8$ were used as dissolution mediums in a volume of $900 \mathrm{ml}$ at $37 \pm$ $0.5^{\circ} \mathrm{C}$. Volume of $5 \mathrm{ml}$ was withdrawn on time scheduled basis of $5 \mathrm{~min}$ from starting, then replaced by fresh media of dissolution, up to $60 \mathrm{~min}$. Samples were filtered using 0.22 micro filter syringe $(0.22$ $\mathrm{Mm})$. Filtrate absorbance recorded by UV analysis versus blank $(0.1 \mathrm{NHCl}$ and phosphate buffer $)$.
Depending on a calibration curve, percentage cumulative release was calculated at $242 \mathrm{~nm}$ and 240 $\mathrm{nm}$, respectively ${ }^{(18-20)}$.

\section{Freeze drying of nanosuspension}

Freeze drying used to convert the optimum formula to dry powder, later for further evaluation. Mannitol used as a cryoprotectant at 3\% w/v. About $400 \mathrm{ml}$ of optimized formula prepared and freeze dried to yield a dry powder for evaluation. Four flasks frozen in a deep freezer at $-20^{\circ} \mathrm{C}$ for $24 \mathrm{hr}$. The frozen flasks were attached to the vacuum port of the device, then four flasks each containing $100 \mathrm{ml}$ of nanosuspension, instrument operated till 
dry powder yielded. Sublimation of solvent from frozen samples took $48-72 \mathrm{hr}^{(8)}$.

\section{Characterization of lyophilized powder Saturation solubility of lyophilized powder}

Three dissolving solvents water, $0.1 \mathrm{~N} \mathrm{HCl}$ and phosphate buffer $\mathrm{pH} 6.8$ were used to investigate the saturation solubility of atorvastatin calcium dried nanosuspension powder. An excess amount of drug was added to each test tube containing the above mentioned solvents then were shaken for at least $48 \mathrm{hr}$ in a water bath shaker at 25 ${ }^{\circ} \mathrm{C}$. Then filter with a conventional filter paper before spectrophotometric reading for each sample. Sample test tubes were centrifuged at $6000 \mathrm{rpm}$ for 15 min. Absorbance of supernatant was recorded and a calibration curve was used to determine the amount of drug dissolved in the specific volume of each dissolving media ${ }^{(21)}$.

\section{Crystallinity and surface morphology $X$-ray powder diffraction}

X-ray diffraction analysis demonstrates the proportion of an amorphous form of the end product powder and endorsed by differential scanning calorimetry.

\section{Differential scanning calorimetry (DSC)}

Differential scanning calorimetric reading performed by PerkinElmer DSC thermal analyzer in an operating temperature from 50 to $250 \mathrm{C}$ ranges at rate of heating of $10 \mathrm{C} / \mathrm{min}$ in nitrogen gas. By computerized DSC software heat of fusing and melting temperature were determined ${ }^{(22)}$.

\section{Scanning electron microscopy (SEM)}

SEM images the surface of solidified sample. Information recorded by the signal such as surface topography, outer layer morphology, compositional chemistry, crystallinity of the particulate and electrical conductivity.

\section{In-vitro dissolution versus pure atorvastatin calcium powder}

In-vitro dissolution of nanosuspension powder was done by USP dissolution apparatusType II. Weight equivalent to $20 \mathrm{mg}$ of atorvastatin calcium nanosuspension powder was mixed with diluents. Mannitol was used as a diluent, and filled into 0 size hard gelatin capsule. At the same time pure atorvastatin calcium powder $20 \mathrm{mg}$ mixed with mannitol and filled into 0 size hard gelatin capsule. $900 \mathrm{ml}$ of dissolution medium, phosphate buffer $\mathrm{pH}$ 6.8 were prepared, filled into two jars of apparatus. Device operated at $75 \mathrm{rpm}$ and $37^{\circ} \mathrm{C}$. Samples were withdrawn regularly with a time schedule and filtered by $0.22 \mathrm{Mm}$ filter syringe. At $246 \mathrm{~nm}$ US spectrophotometer absorbance was measured and the concentration was obtained from a calibration curve ${ }^{(23)}$.

\section{Stability study}

The stability study of the selected formula of ATR nanosuspension F18 lyophilized powder studied and determined using Arrhenius plot. Three various temperatures $\left(40,50\right.$ and $\left.60^{\circ} \mathrm{C}\right)$ applied for 12 weeks storage. Periodically every 2 weeks samples were withdrawn from each temperature and percentage remaining at each capsule was determined by spectrophotometric method,

\section{Results and Discussion}

All the prepared formulas of atorvastatin calcium nanosuspension as shown in table 1 were revealed variation in particle size affected by factors of formulation specified previously.

Total five stabilizer types were used in three different concentrations to prepare nanosuspension; two grades of hydroxypropylmethyl cellulose HPMC E5 and HPMCE15, polyvinyl pyrrolidone (PVP-K30), Tween80 and tocopherol polyethylene glycol succinate (TPGS).

For cellulosic derivative stabilizers, HPMC E5 and HPMCE15, average particle size obtained is $930 \mathrm{~nm}$ for highest ratio of drug: stabilizer, at highest ratio for HPMC E5 only. Not all concentrations yielded nano size, while increasing concentration yielded in more size reduction of the formed nano-particulate due to better adsorbance allowed on formed nanosuspension (24). These results made the stabilizer to be selected for further preparations to investigate the impact of concentration, temperature reduction, co-stabilizer addition and increasing shearing force by homogenization at higher shearing speed, $3000 \mathrm{rpm}$ instead of $1500 \mathrm{rpm}$. HPMC E5 and HPMC E15 used, and two grades both showed the same habit regarding particle size reduction.

Particle size reduction by the use of Polyvinyl pyrrolidone k30 (PVP-K30) measured by particle size analyzer and obtained results revealed that better nano size reduction achieved by this polymer, in comparison to previous one, and highest concentrations of up to 1:1 ratio resulted in lower average particle size which was $100 \mathrm{~nm}$ when measure by Nanobrook haven particle size analyzer. This stabilizer's specifications and used concentration implemented critical role in producing a stable nanosuspension ${ }^{(19)}$.

Polysorbates ( Tween80) and vitamin E derivative ( TPGS ), two water soluble non-ionic surfactants were used, resulting particle measurements displayed that Tween 80 and TPGS didn't yielded nano size particulates at drug to surfactant ratio of 1:0.5 (1932 nm and $3551 \mathrm{~nm}$, respectively). Higher drug to stabilizer ratios, drug to stabilizer ratio $1: 1$, revealed totally different outcomes. Particle size obtained with tween 80 and TPGS both at high concentrations was $493 \mathrm{~nm}$ and $835 \mathrm{~nm}$, respectively. 
Nanosuspension stabilized by steric stabilization due to polymer adsorbance onto particulate surface, polymeric type stabilizers used (HPMC and PVP) and non-ionic surfactants (tween80 and vitamin E-TPGS).

Particle size range obtained from the application of five different stabilizers showed high variability from micron to nano size, this ascribed to the affinity of binding stabilizer molecule to drug molecule ${ }^{(3)}$. Efficient prevention of particle size regrowth and agglomeration of precipitated nanosuspension is the result of stabilizer adsorption onto nanoparticulate. From another point, mechanism of nanosuspension stabilization whether steric or electrostatic or mix of both, is of critical significance of particle size stability maintenance (25). Figure (2 and 3) show the influence of using different types of stability on release profile. To consider the influence of co-stabilizer addition on the particle size reduction and polydispersity index, formulations F16, F17, F18, F19, F20 and F21 were prepared and evaluated for their particle size and PDI. Polymers those act by steric stabilization, HPMC E5, PVP K-30 and vitamin E TPGS were selected as primary stabilizers with two non-ionic surfactant as co-stabilizers Tween 80 act by steric stabilization and anionic surfactant sodium lauryl sulphate act by electrostatic stabilization. Figures (4 , 5,6, and 7) showed the importance of using different types of co-stabilizers on release profile at $0.1 \mathrm{~N} \mathrm{HCl}$ and $\mathrm{pH} 6.8$.

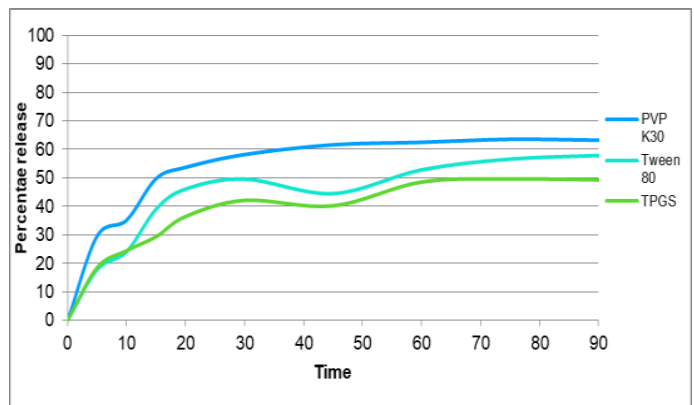

Figure 2. Influence of stabilizer type on release profile of nanosuspension in $0.1 \mathrm{~N} \mathrm{HCl}$ and $37^{\circ} \mathrm{C}$

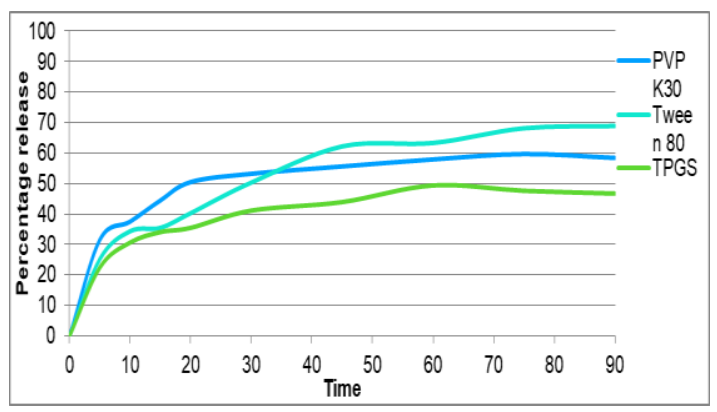

Figure 3. Influence of stabilizer type on release profile of nano-suspensions in phosphate buffer (pH 6.8 ) and $37^{\circ} \mathrm{C}$

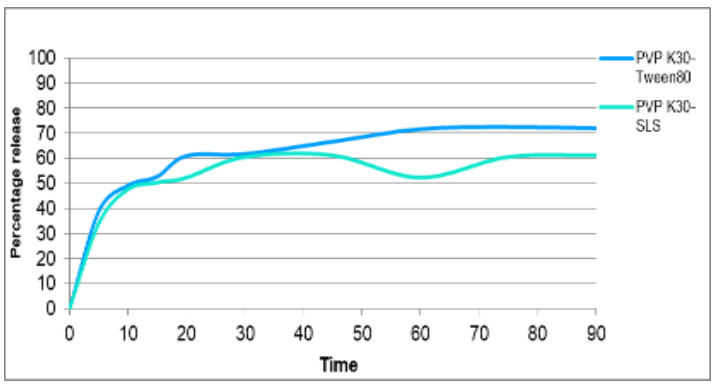

Figure 4. Influence of addition of co-stabilizer to PVP K30 on release profile in $0.1 \mathrm{~N} \mathrm{HCl}$ and $37^{\circ} \mathrm{C}$

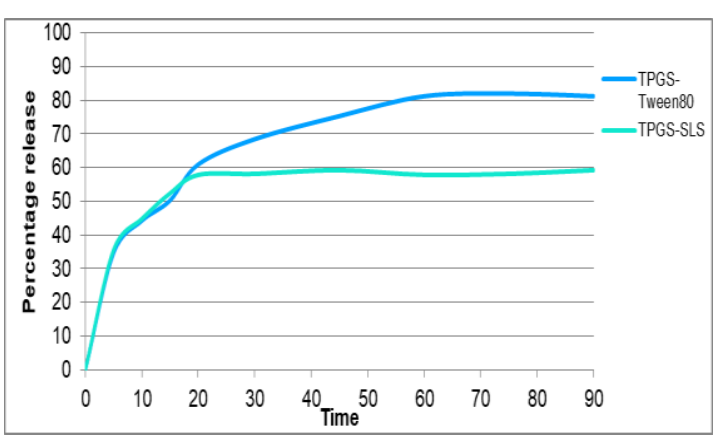

Figure 5. Effect of co-stabilizer to TPGS on release profile in $0.1 \mathrm{~N} \mathrm{HCl}$ and $37^{\circ} \mathrm{C}$

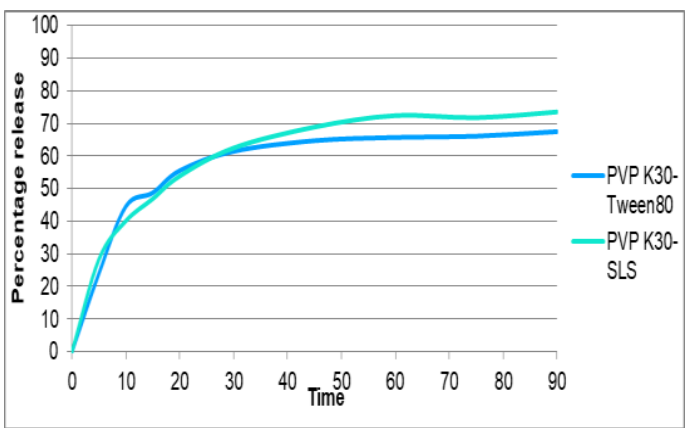

Figure 6. Influence of addition of co-stabilizer to PVP K30 on release profile in phosphate buffer (pH 6.8 ) and $37^{\circ} \mathrm{C}$

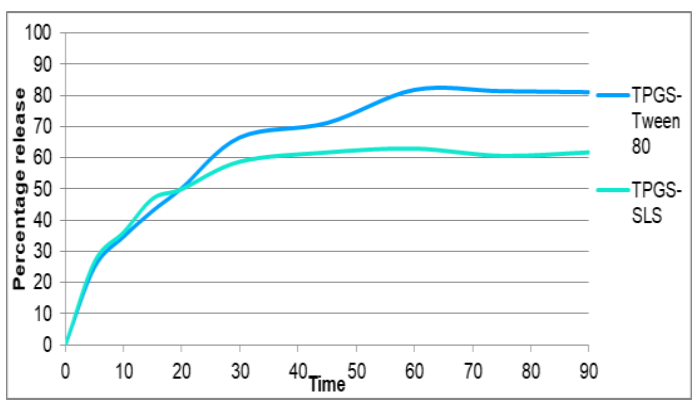

Figure 7. Effect of co-stabilizer to TPGS on release profile in phosphate buffer ( $\mathrm{pH} 6.8$ ) and $37^{\circ} \mathrm{C}$ 
HPMC E5 containing preparation as primary stabilizer in formula F1 (930 nm), addition of nonionic surfactant Tween80 as a co-stabilizer demonstrated further reduction of formulated particulate size to $685 \mathrm{~nm}$. While with formula F19 inclusion of sodium lauryl sulfate resulted in a dramatic reduction of particle size to $166 \mathrm{~nm}$. This result similar to the effect of inclusion of second stabilizer in the formulation of simvastatin nano suspension by Vikram et al. ${ }^{(19)}$. Addition of SLS as a second stabilizer yielded a favorable nano size particulates with improved solubility and stability.

Polyvinyl pyrrolidone PVP K-30 containing formulation F7 $(100 \mathrm{~nm})$ as a primary stabilizer acts by steric stabilization, while inclusion of Tween 80 as co-stabilizer in F17 yielded particle size $246 \mathrm{~nm}$, the similar results out of expectations with inclusion of SLS anionic surfactant noted, electrostatic stabilizer, that resulted in larger particle size on particle size analysis. This was attributed to that PVP k30 is a short chain polymer, so on addition of another co-stabilizer SLS anionic and Tween80 non-ionic surfactant polymer efficient adsorbance onto precipitation particulate disrupted by presence of these surfactants. Addition of both co-stabilizers exhibited enlargement of nanoparticle size in comparison with the formulations included only the primary polymer ${ }^{(26)}$.

Regarding the formulation F13 containing Non-ionic surfactant Vitamin E TPGS derivative, particle size evaluation revealed $835 \mathrm{~nm}$ particle sizes within Nano range. After inclusion of amphiphilic nature non-ionic surfactant Tween 80 as co-stabilizer in F18, with a ratio of drug: stabilizer: co-stabilizer of 1: 1 : 0.5 , particle size reading disclosed $81 \mathrm{~nm}$. Addition of co-stabilizer acting with the same mechanism of stabilization as steric stabilizer showed significant size reduction from the primary polymer when used alone ${ }^{(4)}$.

Another co-stabilizer tested with the primary stabilizer, which is anionic surfactant sodium lauryl sulfate SLS, act by electrostatic mechanism of nano particulate stabilization.

F21 formulated and contained both stabilizer and co-stabilizer mentioned above by 1:0.5 ratios. Particle size measurement demonstrated formation of nanosuspension of $101 \mathrm{~nm}$ which was about eight times size reduction, a size of desired nanoparticulate range.

The addition of co-stabilizer with the primary one to obtain a mix of steric and electrostatic mechanisms of stabilizer of the precipitated nanosuspension is a successful way to formulate a nanosuspension with desired particle size range ${ }^{(27)}$. Binding of nonionic surfactant to nanoparticulate is more tight and adsorption rapid example Tween80 and TPGS ${ }^{(28)}$.
Influence of homogenization speed was mostly clear with HPMC E5 cellulosic polymer, size measurement of formula F1 is $930 \mathrm{~nm}$ operated at a rotation speed of about $1500 \mathrm{rpm}$, while size reduced to 366 at formula F22 on $3000 \mathrm{rpm}$ rotation speed. The improvement in size of formed nanoparticulate explained by viscosity of cellulosic polymers in aqueous solutions reduced as speed of homogenization increased, allowing better stabilizer adsorbance onto precipitated particulate surface exerting better stabilizing effect to nano particulate (29).

Effect of temperature of procedure is evaluated on the particle size produced on formulation of nanosuspension. Formulations F27, F28, F29, F30 and F31 prepared at $10^{\circ} \mathrm{C}$ and tested for particle size produced and PDI of formulations. Formulations containing PVP K30, TPGS and Tween80 prepared at low temperature $10^{\circ} \mathrm{C}$ revealed reductions in the size of formed nanosuspension measurements reported to be $93 \mathrm{~nm}$, $92 \mathrm{~nm}$ and $77 \mathrm{~nm}$, respectively.

Results of this evaluation similar to the outcomes of approach by Pang et al, they tested the influence of temperature, ripening time and calcination on the morphology and crystallinity of hydroxyapatite nanoparticles ${ }^{(30)}$.

Particle size measurement for formulations F27 and F28 included HPMC E5 and E15, respectively, revealed contrary results as the formed formulations was turbid and obvious agglomerations were seen by eye. Polymer solubilization problem and solution viscosity presented rapid change noted at low temperature of operation. Since the agglomerations were observed by eye, no particle size measurement approached for these to formulations this was related to increment in aqueous phase viscosity of the formula ${ }^{(30)}$.

Characteristics of surface charge studied to assess the stability of prepared nano suspensions. As reported in table 2 Estimates of this charge represents nanosuspension stability at macroscopic extent. Minimum limit needed for electrostatic stabilization of Nano suspensions is $+30 \mathrm{mV}$, and for steric stabilization of $+20 \mathrm{mV}$.

\section{In-Vitro dissolution study of atorvastatin calcium nanosuspension}

Figures (2-9) showed the in-vitro release study in addition to freeze dried F18 and pure atorvastatin calcium powder. While table 3 demonstrates the release data recorded for formulas F17 and F18 which were selected for in-vitro release study at $0.1 \mathrm{~N} \mathrm{HCl}$ and phosphate buffer $\mathrm{pH} 6.8$. 
Formula nominated F18 showed highest release of atorvastatin calcium within 60 minutes of study, containing TPG as primary stabilizer and Nanosuspension stabilization is a mix of steric-steric and steric-electrostatic mechanisms. F18 included TPGS which act sterically to stabilize the precipitated nanoparicles by adsorbance onto newly formed nanoparticles.

Inclusion of tween 80 , acting by the same mechanism of steric stabilization, reduced the ratio of primary and co-stabilizer needed to obtain the particle size yeilded $(81 \mathrm{~nm})$ and allowed for better adsorbance onto particulate surface. Reduced concentration of used polymers also permitted better desorption from the particulate surface on the start of dissolution process, So resulting in higher release profile of F18.

Figure 8 and 9 show the in-vitro release profile after freeze drying of selected F18, in comparison to pure atorvastatin calcium powder. Results outlined that freeze dried nanosuspension powder release profile reached maximum at 60 minutes about $81 \%$ at $0.1 \mathrm{~N} \mathrm{HCl}$ and $89 \%$ at pH6.8 phosphate buffer, While pure powder comparative release profile resulted in $35 \%$ release at 60 minute in $0.1 \mathrm{~N} \mathrm{HCl}$ and $44 \%$ in phosphate buffer $\mathrm{pH} 6.8$.

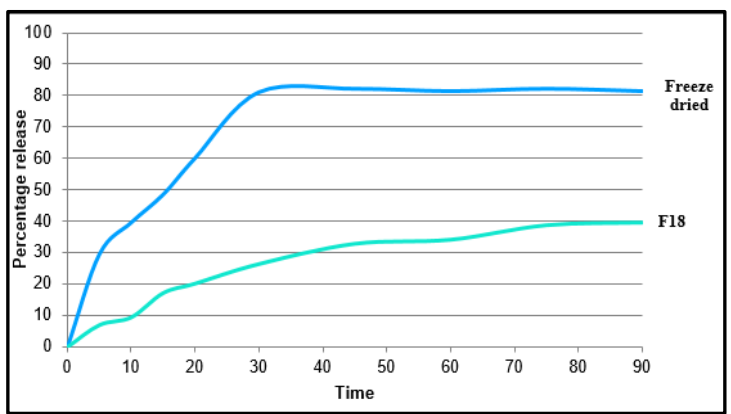

Figure 8. Release profile of freeze dried atorvasatatin calcium nanosuspension formulation compared to pure atovastatin calcium powder in $0.1 \mathrm{~N} \mathrm{HCl}$ and $37^{\circ} \mathrm{C}$.

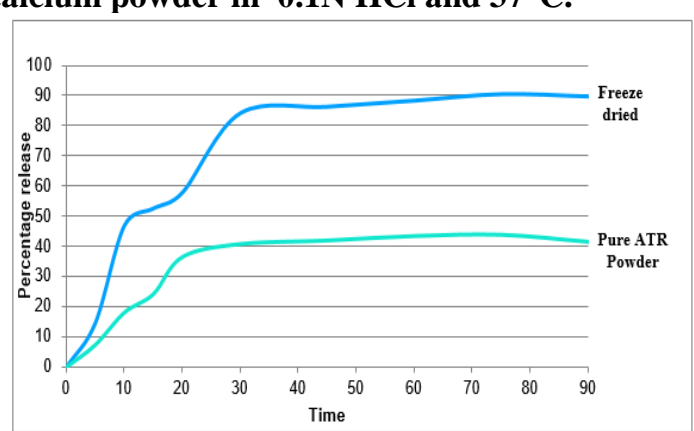

Figure 9. Release profile of freeze dried atorvastatin calcium nanosuspension formulation compared to pure atorvastatin calcium powder in phosphate buffer (pH 6.8 ) and $37^{\circ} \mathrm{C}$
Tween 80 added as a co-stabilizer. Maximum release within 60 minutes reached $81 \%$ and $82 \%$ for $0.1 \mathrm{~N}$ $\mathrm{HCl}$ and 6.8 phospate buffer, respectively.

Using similarity factor for analyzing release pattern of formulaions $\mathrm{F} 17$ and F18 in comparism with pure atorvastatin calcium powder. F2 value higher than 50(50-100) indicates similarities of dissolution profiles, while results of comparison of F17 and F18 with pure atorvastatin calcium powder according to table 3 below revealed values lower than 50 that indicates dissimilarity between dissolution profile of F17 and F18 in regard to pure atorvastatin calcium powder.

Table 3. Similarity factor for F17 and F18 in comparison with pure powder of atorvastatin calcium, highest release profile of studied formulations.

\begin{tabular}{|l|l|l||}
\hline Formula & $\begin{array}{l}\text { F in 0.1 N } \\
\text { HCl }\end{array}$ & $\begin{array}{l}\text { F in 6.8 } \\
\text { buffer }\end{array}$ \\
\hline F17 & 27.05 & 38.91 \\
\hline F18 & 29.41 & 36.85 \\
\hline
\end{tabular}

Lyophilized liquied nanosuspension powder characterized for saturation solubility of atorvastatin calcium in different media including water, $0.1 \mathrm{~N} \mathrm{HCl}$ and phosphate buffer $\mathrm{pH}$ 6.8. The results are demonstrated in table 4 . The increase in saturation solubility in distilled water, $0.1 \mathrm{~N} \mathrm{HCl}$ and 6.8 phosphate buffers were $3.3,3.8$ and $3.7 \mu \mathrm{g} / \mathrm{ml}$, respectively. 
Table 4. Saturation solubility of freeze dried nanosuspension F18 atorvastatin calcium in comparison with pure powder.

\begin{tabular}{||l|c|c|c||}
\hline Solvent & $\begin{array}{c}\text { Pure powder } \\
\text { saturation solubility } \\
\text { mcg/ml }\end{array}$ & $\begin{array}{c}\text { Freeze dried } \\
\text { nanosuspension } \\
\text { saturation solubility mcg/ml }\end{array}$ & $\begin{array}{c}\text { No. of folds } \\
\text { increased }\end{array}$ \\
\hline Water & 135 & 435 & 3.3 \\
\hline 0.1N HCl & 167 & 628 & 3.8 \\
\hline phosphate buffer pH6.8 & 228 & 849 & 3.7 \\
\hline
\end{tabular}

Drug content in freeze dried atorvastatin calcium nanosuspension specified by measurement of absorbance at UV spectrophotometer at $246 \mathrm{~nm}$ after dissolving in methanol. The value revealed that each $100 \mathrm{mg}$ of freeze dried powder contained $6.66 \mathrm{mg}$ of atorvastatin calcium

X-ray diffraction demonstrated sharpe peaks of freeze dried powder of atorvstatin calcium nanosuspension and maintenance of crystal form of the powder with increased solubility and dissolution pattern. Figure (10 and 11) XRD test reports of lyophilized nano suspension.

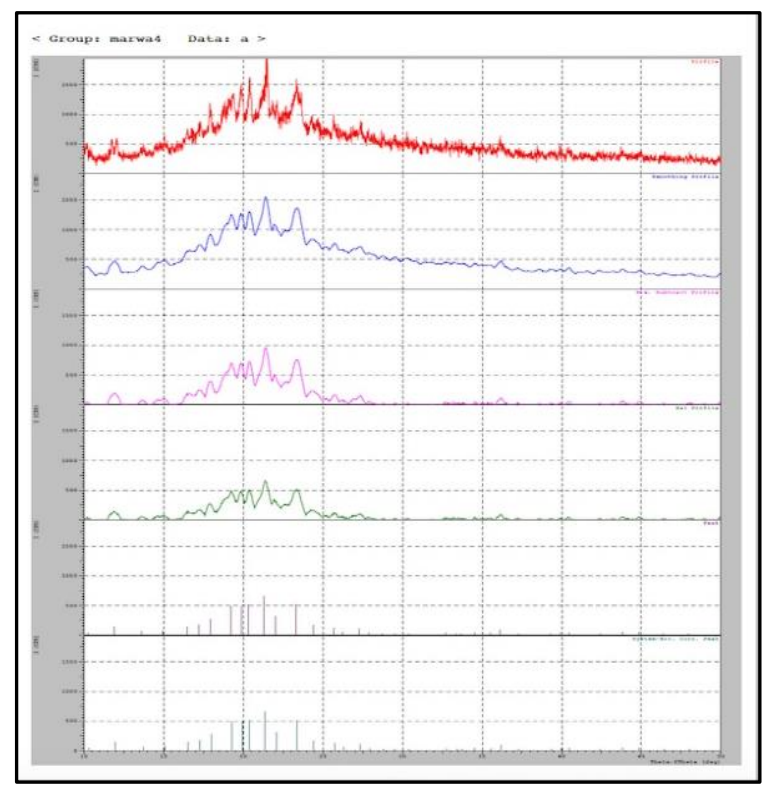

Figure 10. XRD characteristic peaks of atorvastatin calcium nanosuspension

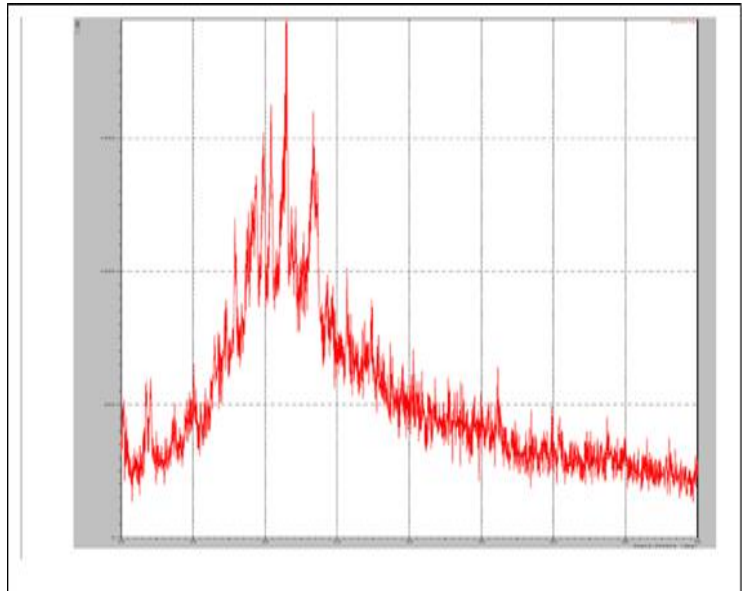

Figure 11. XRD highest intensity peaks of atorvastatin calcium nanosuspension.

DSC thermogram of atorvasatin calcium nanosuspension reported in figure $12(\mathrm{~A}$ and $\mathrm{B})$. The thermogram represented a specific dropping peak at $159.96^{\circ} \mathrm{C}$, which is very close to the melting point of pure atorvastatin calcium powder that reported to be $165.5^{\circ} \mathrm{C}$ on electrical melting point instrument (23).

To examine surface morphology of prepared nanoparticulates and shape, scanning electron microscope was used.

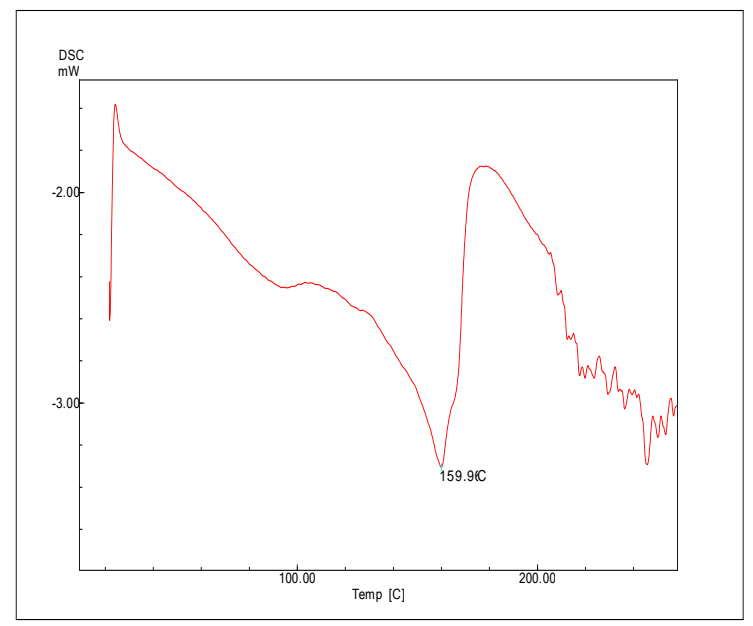

Figure 12. (A) DSC thermogram For F18 atorvastatin calcium nanosuspension 


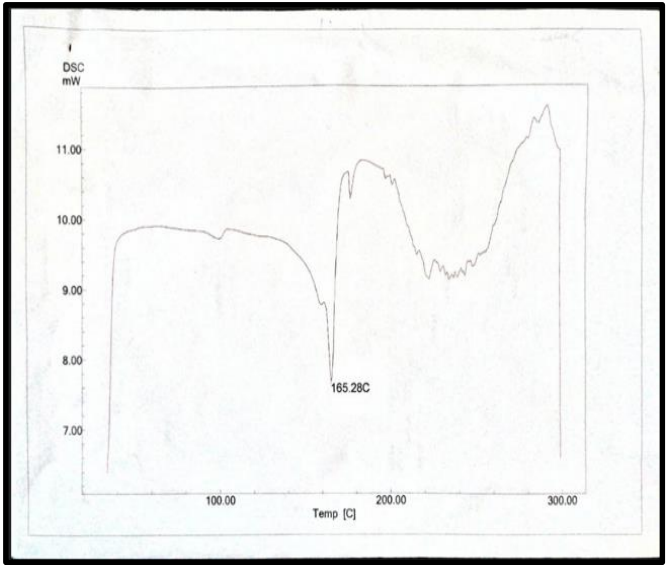

Figure 12. (B) DSC thermogram of atorvastatin calcium pure powder.

Formulation F18 containing TPGS/Tween80 was chosen for scanning electron microscope examination, images at figure 13 (A and B ) demonstrates clear crystal shape and morphology. The same results of crystal nature appeared on XRD and DSC that referred to crystal form of the yielded powder.

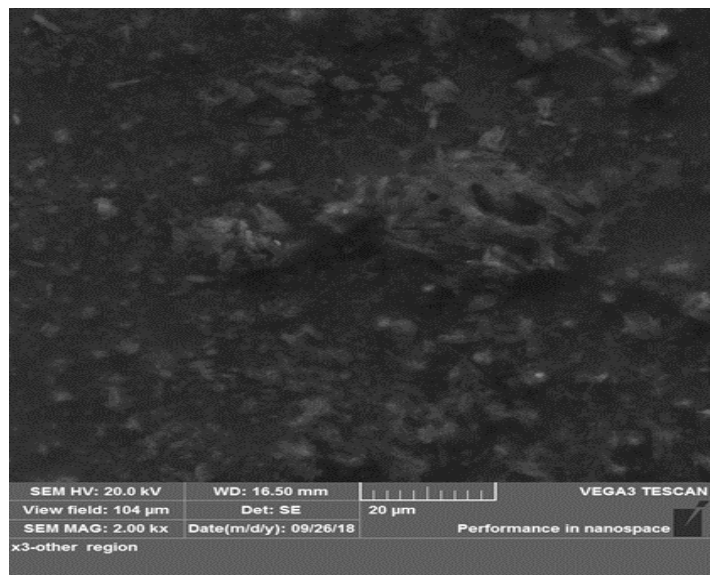

A

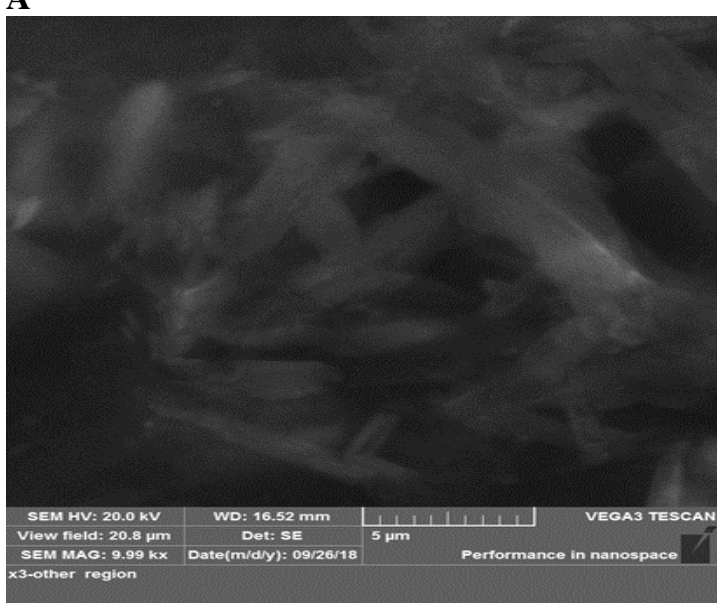

B

Figure13. A and B , illustrates crystal morphology of atorvastatin calcium nanosuspension under scanning electron microscope.

After freeze drying of F18 nanosuspension, yielded powder evaluated for release pattern and compared with pure ATR calcium powder. Release profile of freeze dried nanosuspension F18 revealed $81 \%$ and $89 \%$ release at minute 60 of starting dissolution apparatus for $0.1 \mathrm{~N} \mathrm{HCl}$ and 6.8 phosphate buffer, respectively. Compared to pure ATR calcium pure powder release profile, achieved release of maximum $35 \%$ and $44 \%$ at 60 minute in $0.1 \mathrm{~N} \mathrm{HCl}$ and pH6.8 phosphate buffer as shown in figure 8 and 9 , respectively.

In 1996, Moore and Flanner proposed two indices, or fit factors, to compare dissolution profiles in a pairwise fashion. These indices are known as the difference factor (f1) and the similarity factor (f2). To accurately compare two profiles using these fit factors, the dissolution results should be obtained at a sufficient number of time points to adequately characterize the shape of the dissolution profiles. Because the mean dissolution profiles are compared using these fit factors, the variability associated with the dissolution results of the individual dosage forms at each time point must also meet certain regulatory criteria.

The f1 factor calculates the percent difference between the two dissolution profiles at each time point and is a measurement of the relative error between the two profiles using the following equation:

$$
f_{1}=\left(\frac{\sum_{t=1}^{n}\left|R_{t}-T_{t}\right|}{\sum_{t=1}^{n} R_{t}}\right) \times 100
$$

where $\mathrm{n}$ is the number of time points, $\mathrm{Rt}$ is the mean dissolution value for the reference product at time $t$, and $\mathrm{Tt}$ is the mean dissolution value for the test product at that same time point.

The f1 value is equal to zero when the test and reference profiles are identical and increases as the two profiles become less similar.

The $\mathrm{f} 2$ factor is a logarithmic reciprocal square root transformation of the sum of squared error and is a measurement of the similarity in the percent dissolution between the two profiles as in the following equation ${ }^{(31)}$.

$$
f_{2}=50 \times \log _{10}\left[\frac{100}{\sqrt{1+\frac{\sum_{t=1}^{n}\left(R_{t}-T_{t}\right)^{2}}{n}}}\right]
$$

Application of similarity factor in comparing release profile of freeze dried nanosuspension with pure ATR calcium powder resulted in values lower than 50 in both $0.1 \mathrm{~N} \mathrm{HCl}$ and pH6.8 phosphate buffer as shown in table 5 . 
Table 5. Similarity factor $f_{2}$ for $\mathbf{F 1 8}$ freeze dried nanosuspension in two solvent ( $0.1 \mathrm{~N} \mathrm{HCl}$ and phosphate buffer pH 6.8 ) in comparison with pure drug

\begin{tabular}{|l|c|c||}
\hline Formula & $\begin{array}{c}\text { F in 0.1 N } \\
\text { HCl }\end{array}$ & $\begin{array}{c}\text { F in } \\
\text { phosphate } \\
\text { buffer pH 6.8 }\end{array}$ \\
\hline $\begin{array}{l}\text { F18 freeze } \\
\text { dried }\end{array}$ & 23.85 & 25.98 \\
\hline
\end{tabular}

\section{Stability study}

Figure 14 shows the plot of the logarithm percent remaining of ATR calcium versus time (week) at different temperatures. The obtained profiles were linear, indicating that ATR calcium degradation follows first order kinetics. The degradation rate consistent $(\mathrm{K})$ at every temperature was resolved from the slope of every line.

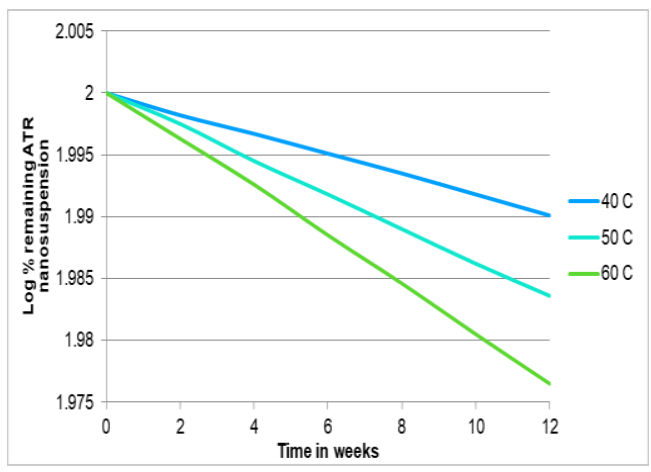

Figure 14. Rate of degradation of atorvastatin calcium nanosuspension freeze dried powder stored at three various temperatures.

For estimation of degradation rate constant $\mathrm{K}$ at $25^{\circ} \mathrm{C}$, Arrhenius plot, (Figure 15), constructed by ploting $\log \mathrm{K}$ versus temperature in Kelvins. So the value of (K25) was calculated ( 0.0009 week $\left.^{-1}\right)$

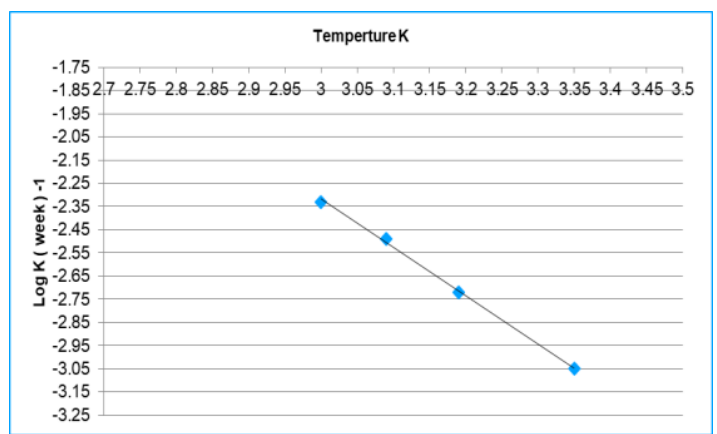

Figure 15. Arrhenius plot of freeze dried ATR nanosuspension for determination of degradation rate constant at $25^{\circ} \mathrm{C}(\mathrm{K} 25)$.
As the decomposition of the drug compliant with first order kinetics, the accelerated expiration date can be computed using the following equation ${ }^{(30)}$ : $\mathrm{t}_{90} \%=0.1054 / \mathrm{K} 25$

Where $t_{90} \%$ is the time needed for a drug to have $10 \%$ of its potency lost, and it was found to be 2.24 years.

\section{Conclusions}

Formulating atorvastatin calcium conventional powder as nanosuspension significantly $(\mathrm{p}<0.05)$ increased solubility and improved rate of dissolution in the final dosage form.

\section{References}

1. Agrawal et al. Nanosuspension: An approach to enhance solubility of drugs. Journal of Advanced Pharmaceutical Technology \& Research, (2011); 2(2), 81.

2. Prabhakar, C., \& Bala Krishna, K. A review on nanosuspensions in drug delivery. International Journal of Pharma and Bio Sciences, (2011); 2(1), 549-558.

3. Choi et al. Role of polymeric stabilizers for drug nanocrystal dispersions. Current Applied Physics 2005;5(5): 472-474.

4. Bodmeier, R., \& Huagang, C. Indomethacin polymeric nanosuspensions prepared by microfujidization. Journal of Controlled Release 1990; 12(3): 223-233.

5. Bhanu P. Sahu o Malay K. Das. Nanosuspension for enhancement of oral bioavailability of felodipine. Appl Nanosci (2014) 4:189-197.

6. Lee, J.. Intrinsic adhesion force of lubricants to steel surface. Journal of Pharmaceutical Sciences2004; 93(9): 2310-2318.

7. Wang, Y et al. Stability of nanosuspensions in drug delivery. Journal of Controlled Release2013; 172(3):1126-1141.

8. Gadad, a P., Chandra, P. S., Dandagi, P. M., \& Mastiholimath, V. S. Moxifloxacin Loaded Polymeric Nanoparticles for Sustained Ocular Drug Delivery. Journal of Pharmaceutical Sciences2012; 1727-1:734.

9. Tank, X., \& Pikal, M. Design of Freeze-Drying Processes for Pharmaceutical : Practical Advice. Pharmaceutical Research 2004; 21(2).

10. Van Eerdenbrugh, B., Froyen, L., Van Humbeeck, J., Martens, J. A., Augustijns, P., \& Van den Mooter, G. Drying of crystalline drug nanosuspensions-The importance of surface hydrophobicity on dissolution behavior upon redispersion. European Journal of Pharmaceutical Sciences2008; 35(1-2): 127135.

11. Roche, V. F. Antihyperlipidemic statins: A selfcontained, clinically relevant medicinal chemistry lesson. American Journal of 
Pharmaceutical Education2005; 69(4): 546560.

12. Xia, D., Quan, P., Piao, H., Piao, H., Sun, S., Yin, Y., \& Cui, F. Preparation of stable nitrendipine nanosuspension using the precipitation-ultrasonication method for enhancement of dissolution and oral bioavailability. European Journal of Pharmaceutical Sciences2010; 40(4): 325-334.

13. Pande, V. V., \& Abhale, V. N. Nanocrystal technology: A particle engineering formulation strategy for the poorly water soluble drugs. Der Pharmacia Lettre2016; 8(5): 384-392.

14. Pandya et al. Formulation, optimization and characterization of simvastatin nanosuspension prepared by nanoprecipitation technique. Der Pharmacia Lettre2014; 3(2): 129-140.

15. Kronberg et al. Preparation and evaluation of sterically stabilized liposomes: Colloidal stability, serum stability, macrophage uptake, and toxicity. Journal of Pharmaceutical Sciences1990; 79(8): 667-671.

16. Esfandi, E., Ramezani, V., Vatanara, A., Najafabadi, A. R., \& Hadipour Moghaddam, S. P. Clarithromycin dissolution enhancement by preparation of aqueous nanosuspensions using sonoprecipitation technique. Iranian Journal of Pharmaceutical Research.2014; 13(3): 809-818.

17. Cerdeira, A. M., Mazzotti, M., \& Gander, B. Formulation and drying of miconazole and itraconazole nanosuspensions. International Journal of Pharmaceutics2013; 443(1-2): 209220.

18. Sahu, B. P., \& Das, M. K. Nanosuspension for enhancement of oral bioavailability of felodipine. Applied Nanoscience2014; 4(2): 189-197.

19. Pandya, V. M., Patel, J. K., \& Patel, D. J. Formulation, optimization and characterization of simvastatin nanosuspension prepared by nanoprecipitation technique. Der Pharmacia Lettre2011; 3(2): 129-140.

20. Shalaby, E. a, \& Shanab, S. M. M. Formulation, optimization and characterization of candesartan cilexetil nanosuspension for in vitro dissolution enhancement. African Journal of Pharmacy and Phamacology2013; 7(10): 528-539.

21. Raval, A. J., \& Patel, M. M. Preparation and Characterization of Nanoparticles for Solubility and Dissolution Rate Enhancement of Meloxicam. International Research Journal of Pharmaceuticals2011; 01(02): 42-49.
22. Kakran, M., Sahoo, N. G., Li, L., Judeh, Z., Wang, Y., Chong, K., \& Loh, L. Fabrication of drug nanoparticles by evaporative precipitation of nanosuspension. International Journal of Pharmaceutics2010; 383(1-2): 285-292.

23. Arunkumar, N., Deecaraman, M., Rani, C., Mohanraj, K., \& Venkateskumar, K. Preparation and solid state characterization of Atorvastatin calcium nanosuspensions for enhanced solubility and dissolution. International Journal of PharmTech Research2009; 1(4): 1725-1730.

24. Liu, Y., Sun, C., Hao, Y., Jiang, T., Zheng, L., \& Wang, S. Mechanism of dissolution enhancement and bioavailability of poorly water soluble celecoxib by preparing stable amorphous nanoparticles. Journal of Pharmacy and Pharmaceutical Sciences2010; 13(4): 589606.

25. Pande, V. V., \& Abhale, V. N. Nanocrystal technology: A particle engineering formulation strategy for the poorly water soluble drugs. Der Pharmacia Lettre2016; 8(5): 384-392.

26. Saeedi, M., Rafati, M. R., Morteza-Semnani, K., Yazdani Rostam, A., \& Kelidari, H. R. Evaluation of effect of Tween80 on characteristics of tadalafil $0.1 \%$ suspension. (2015).

27. Kronberg, B., Dahlman, A., Carlfors, J., Karlsson, J., \& Artursson, P. Preparation and evaluation of sterically stabilized liposomes: Colloidal stability, serum stability, macrophage uptake, and toxicity. Journal of Pharmaceutical Sciences1990; 79(8): 667-671.

28. Kocbek, P., Baumgartner, S., \& Kristl, J. Preparation and evaluation of nanosuspensions for enhancing the dissolution of poorly soluble drugs. International Journal of Pharmaceutics2006; 312(1-2): 179-186.

29. Müller, R. H., \& Peters, K. Nanosuspensions for the formulation of poorly soluble drugs. International Journal of Pharmaceutics1998; 160(2): 229-237.

30. Pang, Y. X., and Bao, X. Influence of temperature, ripening time and calcination on the morphology and crystallinity of hydroxyapatite nanoparticles. Journal of the European Ceramic Society2003; 23(10): 16971704.

31. Dorys Argelia Diaz et al.Dissolution Similarity Requirements: How Similar or Dissimilar Are the Global Regulatory Expectations? The AAPS Journal,2015; DOI: 10.1208/s12248015-9830-9. 